\title{
Adaptive Unified E-learning Approach Using Learning Objects Repository Structure
}

\author{
Nasim Matar \\ Zarqa University, Jordan
}

\begin{abstract}
This paper presents a new structure for adaptive unified e-Learning using a specific object repository structure toward collaborating effort between universities, educational establishment or corporate companies. The need for adaptability in the current e-learning systems has been outlined in many different researches, due to the negative effect of "one-size-fits-all" approach in the development of educational courseware. Different systems have been introduced as prototypes towards providing adaptability in a smaller scope of two or three courses, and no definite solution or a framework has been provided for "Adaptive Unified E-learning Repositories". The objectives of the presented approach is to provide adaptability in unified $e$ learning environments, where more than one university and multiple faculties can participate in adding and updating learning objects such as documents, audio/video files, etc. The systems structure will give the student the privilege of accessing a dedicated learning space where he can view and interact with the course materials that have been adapted to suit his preferred choice of learning style based on different adaptable approaches.
\end{abstract}

\section{Introduction}

The advances in information and communication technologies have provided many services towards educational technologies, especially through the availability of networks and internet technologies. Such technologies have enabled the diversity of pedagogical approaches towards students and learners and it affected the educational process through enhancing the processes, styles and creating new opportunities for sharing and delivering knowledge [1].

The availability of different vendors for software productions with a huge sum of services and resources, thus it was towards educational environments, have also helped many universities towards adopting such applications within their curricula, by which they were able of managing the learning processes, students and distributing course materials by using dedicated learning management systems (LMS) and learning content management systems (LCMS)[2].
However, different software packages have also been used for creating and manipulating learning objects that varied from simple desktop applications (Such as Office applications) to more sophisticated packages that deals with multimedia and interactive learning objects [3]. All the previous mentioned packages, applications and the resulting learning objects, have enriched the educational pedagogy believed that this new educational technology has provided the optimal services for students, instructors and educational institutions, which proved to be false in many cases $[4,5,6]$.

However, as a natural extension to the needs towards categorizing and classifying learning objects for better utilization, sharing and reuse, the learning object repositories were the answer for such demands. Many applications provided the ability for sharing resources among different educational institutions using different techniques and methodologies, ranging from simple structure such as the case of "LionShare" to more advanced approach such as "LonCAPA". The availability of such applications has solved many problems, especially for educational institutions that are lacking the expertise or fund for creating learning objects. It also enabled many educational institutions to provide better means for enhancing the move towards creating and reusing quality learning objects, which helped many instructors lacking the knowledge and expertise for creating such learning objects to be in direct use of the available pool of such educational resources [7].

Even though many educational technologies and services have been provided to enhance the educational pedagogy, but to the contrary of the expected, a fall in the participants and subscribers towards these educational technologies was recorded in many different studies among students and instructors $[4,5,6]$. The previous studies have also identified the reason for such drop, and it was the presence of "one-size-fits-all" towards providing the educational courseware for students in all the previous educational technologies. Thus a demand was raised for shifting the focus towards supporting learner needs and flexibility rather than providing new technological services under the previous effect of "one-size-fits-all” [6,7] . Many adaptive elearning applications where created towards satisfying students needs and learning style using different approaches, but their focus and intent was not towards unified learning object repositories, 
rather it was more to be considered as a prototype towards providing an initial solution to such problem on a small scale covering one or two taught subjects [9]. The need for considering students adaptive needs towards learning resources according to their learning demand is a current need and a must have solution in current and new applications and services[8].

The following sections will draw a clear image of the current repository approaches used and the associated problem of "one-size-fits-all” with such systems. Next, this paper will discuss the distinct solution towards enabling a structure towards providing adaptive learning object resources in unified e-learning repositories.

\section{Unified e-learning repository}

Unified E-learning Repository (UER) is webbased database application software that is used for simplifying the tasks of sharing learning contents and resources between different universities through providing a unified solution and access point. Such systems are capable of providing management information regarding contents and users; in addition they provide instructors and course authors with ability to reuse learning contents and to assemble those learning contents into courses [10]. Different initiatives have been implemented to support the idea of unifying e-learning repositories among different organizations and educational institutions, and each initiation has different approach to provide such services [11].

The idea of UER is to provide an environment to simplify the task of sharing different learning resources. The illustration in Fig. 4 shows that UER provides a repository system that can be accessed by a web portal in order to use or update the learning contents in that repository system. The process of adding or updating the learning contents is approved by administrators by granting each user with the needed privileges. Instructors and media authors are granted privileges of using, reusing and updating the repository with learning contents. On the other hand students are granted privileges to view and interact with the course materials and activities that are provided for them through the system. Each UER has a different approach and activities regarding learning materials and resources. Some UER systems provide users with privileges to copy the course or learning materials into their own LMS or LCMS, while other UES restrict the use of their resources to their own learning network [12]. Instructors are mainly provided with different synchronous and asynchronous tools and activities through which they can contact their peers and share different ideas and discuss different problem. Students are assigned to the system by their instructors or by the administrators of the system as different UER have different approaches regarding the sign up and access process and policies. Students are generally provided with different tools through the systems, through which they can interact with their instructors and peers.

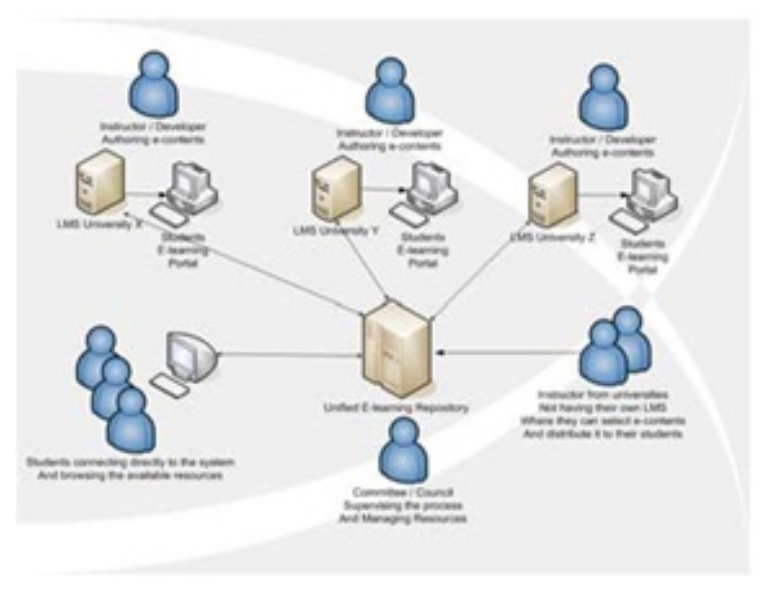

Figure 1. Unified e-learning structure [12]

\section{UER Approaches}

Different approaches have been initiated to support the idea of UER. The first approach is called the Centralized-LCMS Approach. In the simple Centralized-LCMS Approach, a centralized LCMS is used to provide the sharing courses as readymade packages that can be used by instructors. Such approach can be performed using any available LCMS such as (Moodle, ATutor, Blackboard, WebCT,...etc), and a centralized access point will be made available for the participating university through that system [7]. The second approach is called the Networked Approach. The idea of The networked approach is different in focus as it is based on learning objects level rather than readymade courses, so that each instructor can use the learning objects and structure them into their courses [13]. An example to a system that is using the networked approach is called LON-CAPA which stands for Learning Object Network with CAPA [14]. The LONCAPA system provides unified elearning through a dedicated network, and in order for any university to use the system they should structure their servers to be a part of the learning network with special demands for servers' types and software platforms. . LIONSHARE is another UESoriented platform that uses the network method for sharing resources between learners [15]. This program offers the same functionalities as "KAZZA" [16], "BearShare"(http://www.bearshare.com/), "LimWire” [17], and "Gnutella” [18], but it differs in that it requires user authentication before using the system or sharing resources, and in addition the 
program is dedicated for educational environment. LIONSHARE allows file sharing through creating virtual directories into which users can upload files and push them to a remote peer-server. It also enables management of files on those remote servers as they are on the user's local system; moreover, it enables creating access control lists to restrict sharing to a defined group of users to protect users' copyrights. Another program that fit to the same categories of networked UES is "Edutella" [19]. This program was used for exchanging resources between German universities, and it has also been used by Swedish universities and Stanford University.

"SPLASH" [20], is another system that is used as distributed learning objects repository / metadata tagging tool. The system was developed as a part of the "Portal for Online Objects in Learning" (POOL) project, which is a consortium of several educational private and public sector organizations to develop an infrastructure for learning object repositories [28].

\section{One size does not fit}

All of the previously mentioned systems are capable of storing and distributing learning objects for users to enable them of effective sharing of learning contents. Most of the current systems have satisfied instructors' needs for constructing the needed courses along with the needed learning objects and contents. Students as receivers of the provided courses and learning materials have been ignored through not supporting their learning demands and diversity of learning styles. This problem was noticed in most of the systems discussed previously and it was dubbed the "one size fits all” approach [4]. This approach has resulted in a drop in the rate of satisfaction for the current elearning systems and repositories. This problem began with the presence of LMS/ LCMS, as supporting students' needs and learning styles was not considered. Different research studies have produced different solutions based on criteria associated with students' profiles and performance [5]. Such solutions where found to be expensive and hard to implement in the current LCMS, LMS and UER. This problem still exists within the currently used systems and no definite solutions have been provided [2]. Different approaches, including this research, are trying to figure out a definite solution [4,5,6]. Fig. 2 is showing a typical example of the one-size-fits-all problem. As displayed by Fig.2, we can see that the instructor have added a set of different resources to the course he/she is teaching. The resources have been selected and added by the instructor, and these learning resources cannot be change in any mean by students. The students can select or reject or add additional resources to the course structure. Also students are not allowed to add or change any resources into their learning space. So whatever the instructor is serving into his course, the student have to take without being able of choosing different resources from the repositories using different adaptable approaches. The current existence for the courseware material with instructors being the only providers and controller for course structure and resources is what is known by one-size-fits-all problem, which is hindering the adoption percent of e-learning among learners.

\section{Topic outline}
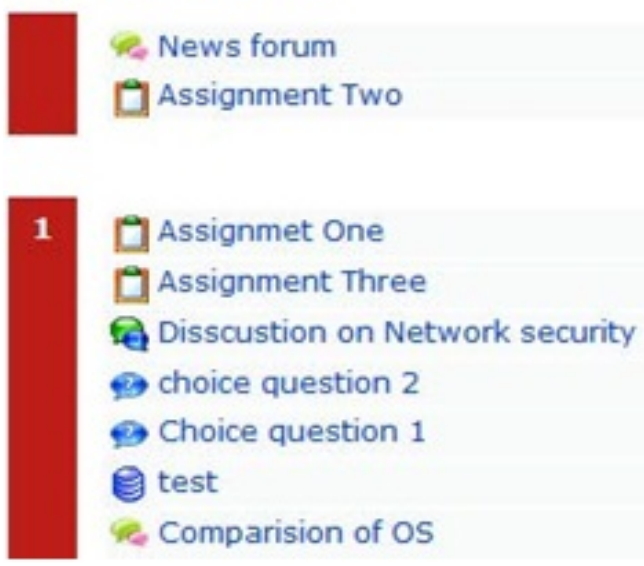

Figure 2. One-size-fits-All in the current courseware

\section{Adaptability concerns}

Different research studies are investigating varieties of methods towards applying adaptability towards students learning styles. These studies are confirming that providing adaptive e-learning would bring better e-learning as facilitated by the pedagogical model provided by each adaptation methodology [22]. Several research studies have been implemented towards providing adaptive educational hypermedia systems such as ACCT [23]. AHA! [24], WINDS [25] and OntoAIMS [8], plus many more different studies that was initiated towards adaptability. The common aim of those studies were to find a solution against the one-sizefits-all problem, and to compensate knowledge deficits, and minimize learner fatigue and discomfort with the subject being taught, thus providing an easier introduction to the topic in hand [23], [24]. Each of the previous approaches has its own theories, methodologies and applications that support the idea of adaptability by defining a unique structure for the provision of such services.

A key difference between the current e-learning solutions and the adaptive e-learning approach is the latter's capacity to allow the production or reuse of different learning objects from which the learner can 
select those that are relevant to his learning necessities with respect to different criteria's [26]. Adaptability in most of the cases is based on of the following criteria's:

- $\quad$ Student initial knowledge.

- Knowledge objectives.

- Preferred learning method based on (Visual, Auditory, Kinaesthetic) Style.

The following approach to the solution of providing adaptability will show the ability of the new Structure implementation towards incorporating the different approaches within one flexible structure towards unified e-learning repository.

\section{A new adaptive structure}

The idea of the system structure consists of different models that provide a new design for the implementation of Adaptive E-learning Repository (AER). For simplicity, the design will be introduced in five simple structures which will later be assembled to form one final structure.

\subsection{Repository structure "The Data Domain Model”}

The repository structure, that represents the "Data Domain Model”, will be responsible for storing the learning objects into a specific designed structure. The structure that will be used by our repository is called the "Book-Structure". It will contain different categories that represent the departments and the courses with respect to each specialization. For example, the IT department will have different courses that are being taught by this department, and each course will consist of different chapters, also each chapter will be constructed of different topics while each topic will have different types of learning objects such as (text, Audio, Video,...etc) that satisfy the topic being taught.

The repositories department and course layout structure can be defined and supervised by a consortium or committee which will consist of subcommittees that define and regulate course layout structure. The following figure shows an illustrated design for the repository data domain model.

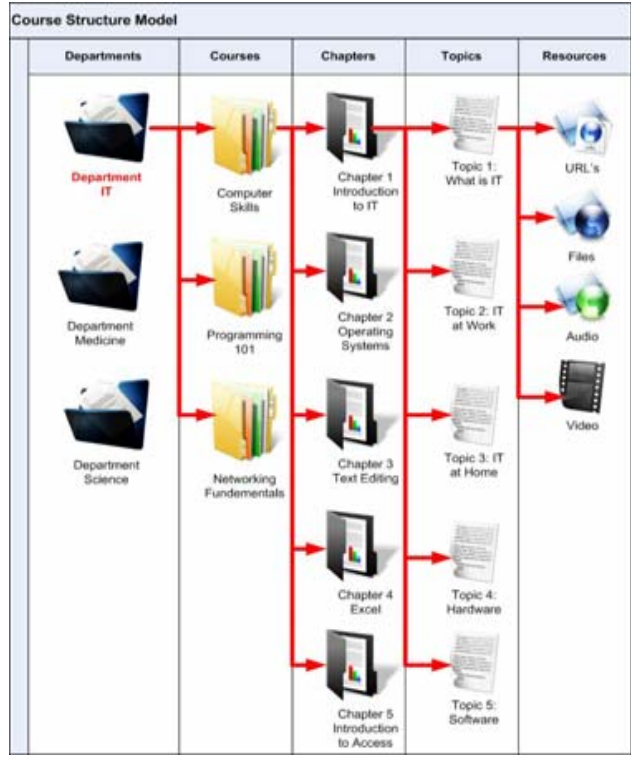

Figure 3. Repository Data Domain Model

The course structure design can be approved by a committee formed from different university to supervise and to advice on the course structure. Such committee will present an outline that merges the suggestions of the experts in the course being taught, so that the course structure can fit and include all the needed chapters and topics required by each university curriculum. The course structure committee will have different responsibilities also, and such responsibilities are presented in the following section.

\subsection{Objectives domain Model}

Constructing the objectives domain model will be another responsibility associated with the "Course Committee", as they are the experts formed by different universities teaching the same course. Each course taught has different objectives that can be listed and associated with course topics in the previous course structure. Making such association will enable the objectives domain model to connect with the topics and learning objects in the course structure. Thus the system will hold two different structures that will be used towards providing adaptability based on students' knowledge objectives approach that will be discussed later in this paper. The following figure shows the structure of the objectives domain model and the way it is associated with the data domain model. 


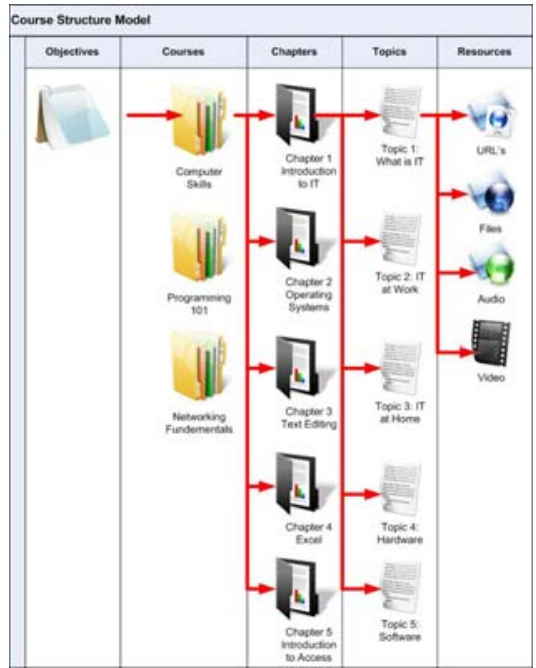

Figure 4. Objectives structure model

\subsection{Assessment domain Model}

The Assessment domain structure will be based on the Data Domain Model as the assessment will be associated with each topic introduced within the course structure. Also the assessments files are treated as different type of learning objects. Instructors using the system will be able to add whatever kind of assessment files and quizzes they have and in different file formats, also and assessment engine will give the ability of creating and constructing quizzes to be associated with each topic in the course structure. Such capability of creating quizzes and assessment modules are available within many different systems such as (Moodle, ATutor,WebCT...etc), also such features come with the capability of setting parameters for pass and fail in the assessment session.

\subsection{Instructors domain Model}

Instructors in the adaptive repository system will have two different responsibilities:

a) They are responsible for uploading different learning objects to the repository data domain model with respect to the structure of the course being formed by the course committee, and those learning objects include learning topics and assessment learning objects.

b) They will be responsible for creating substructures (e-courses) from the main course structure that fits the subjects' requirements for the course being taught according to university's curriculum, or according to the objectives of the course being taught.
The process of adding learning objects to the data domain model will be straight forward, as the instructors will have privileges to add such contents with respect to each topic in the repository structure as it is shown in the following figure.

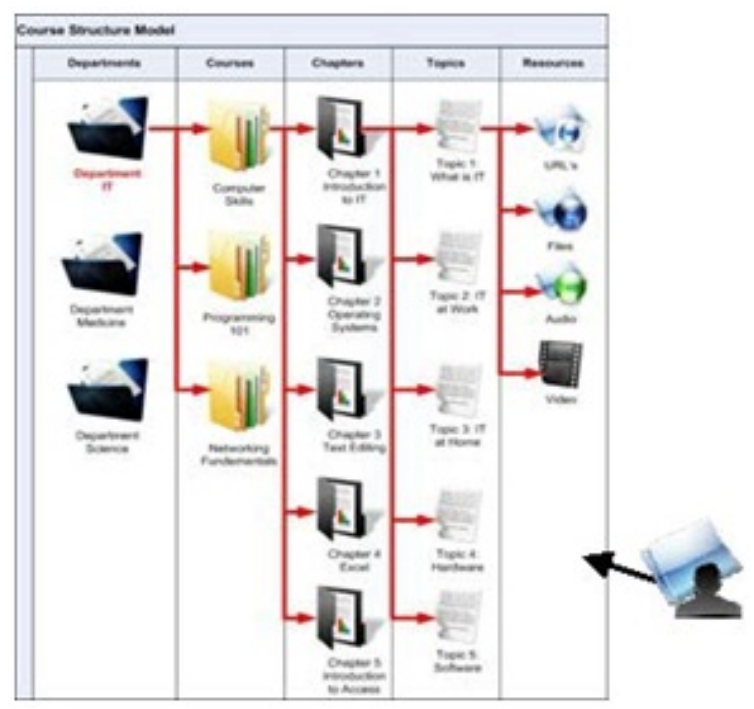

Figure 5. Adding learning objects to Data Domain Model

The process of adding learning objects will be through a dedicated web page, through which the instructor can add a special data about the learning objects or as it is called "Meta-Data". Using "MetaData" with learning objects will enable the repository to use advanced methodologies for searching and displaying learning objects, through incorporating resource data framework (RDF) technology. The scope of this research will not use RDF for learning objects retrieval, but having such flexibility in the repository design, can ensure its maintainability and flexibility for further enhancement on the system.

The process of creating e-courses from the main data domain model will be through performing different easy steps:

a. Identify the department

b. Locate the course

c. Select the needed chapters from the main data repository model, which are required by the course syllabus

d. Select the needed topics from the course with respect to the chapters being selected and the needed course objectives 


\section{e. Select different type of resources with respect for each topic}

To put the process in simpler format, we will have the following example:

Instructor $\mathrm{X}$ has selected the Information Technology department, next he selected (Java) course, then he selected a set of chapters that are required by university syllabus, and the selection process for chapters can be random. So if the main course has 12 chapters, he can make the following random selection, (Chapter1, Chapter2, Chapter4, Chapter6 and chapter8), as required by university's syllabus. Next he will make a random selection for the topics according to each chapter objectives, or the overall objectives of the course. The subsequent step is the random resources selection for each topic, through which the number and ranking of resources can be selected. The final step is to click on a dedicated button that will create his e-course and add it to instructors' domain.

\subsection{Student domain Model}

Students will log to their learning space, and before using the system, they will be required to perform an assessment towards adaptability. Also they need to specify some constraints towards displaying and selecting learning objects such as (maximum file size, maximum number of learning objects retrieved and rank of the learning objects quality). Assessments can be performed using different methods, the system will provide the ability for students to choose any preferred assessment towards adaptability they choose based on the adaptable approaches mentioned previously. The result of the assessment for each approach will be displayed by having the instructor's e-course structure provided with the learning objects that are based on students adaptability results and learning objects constraints specified by the assessment process. Regarding the files choosed by the instructor they will also be displayed in different colour if they does not fit the assessment results, and they will be kept within the student's course structure for future review by student if he chooses to do so.

\subsection{Adaptive assessment engine}

To provide adaptability for students learning styles, an assessment process should be present in the structure before the student can interact with the ecourse or learning objects. As mentioned previously, student-learning-style assessments are done using different methods; this section will provide the adaptability approach discussion with respect for the previous approaches mentioned.

\subsubsection{Student initial knowledge.}

This method will start by the student selecting the course, then specifying instructor, next he will have a random test generated from the assessment engine that will display different quizzes and questions that the student has to answer. Upon the successful completion of the assessments, an electronic course will be generated into students learning space; this course will have similar structure of instructor's ecourse with exception of highlighting the links for the learning objects that are within the current student knowledge and with respect to the constraints added towards maximum learning objects number, size and quality. By having the e-course displayed in such manner, student can use the highlights to guide his learning process, as he will be able to choose the learning objects that satisfies his need based on his initial knowledge in the course he is approaching, thus it will minimize the time and fatigue dealing with the course objects and structure.

\subsubsection{Knowledge objectives.}

By choosing this method, the student will be presented by a list of courses based on the department he chooses. Next, he will be presented by the course objectives list created by the course committee, and he will be able of choosing what knowledge objectives he desires based on a random selection. Next he has to choose the instructor and the course taught, afterwards the assessment engine will produce the students e-course based on three possible scenarios.

- Scenario 1: The student have selected less course objectives than the once offered by instructors ecourse, in this case the instructors e-course structure will be listed as is while highlighting the links that satisfy the objectives in different colour, to indicate the adaptability towards students selected objectives.

- Scenario 2: The student has selected the same course objectives as the once specified by the instructor's e-course structure; in this case the same course structure will be displayed with no change.

- Scenario 3: the Student has selected more objectives than the once offered by the instructors e- course, in this case the main course structure formulated by the committee will be choosed with respect to the objectives selected by the student and the number and quality of resources will be controlled by the constraints selected by the student towards learning objects. Moreover, the assessment engine will make intersection between the selected students e-course based on objectives and the instructor's e-course structure. The result of the intersection will be the final 
students e-course displayed with highlights on the common structure between the student's and instructor's structure. Such highlights will guide the student towards the larning process based on his adaptable preferences.

\subsubsection{Preferred learning method based on (Visual, Auditory, Kinaesthetic) Style}

If the student chooses this method of adaptability assessment, he will be introduced by a set of predefined questions from the assessment engine, which will define the appropriate learning style of the students. The results will be based on numeric percentages for each learning style and thus a percent can be driven for showing the learning objects with respect to the percent value of the assessment. After the student finishes his assessment and specifies the constraints regarding learning objects selection, he will browse the system to locate the needed instructor, and by selecting his instructor, a list of courses taught by the instructor will be displayed. By selecting the appropriate course, a copy of instructor's e-course will be displayed on his learning space. This copy will be an exact copy of the e-course structure plus additional links towards learning object based on his learning style and constraints defined in the assessment. Students can interact with those learning objects, and they will be able of ranking each learning object displayed in the course. Thus ensuring after a time that a quality of resources will be displayed in the repository, which will ease the process of selecting learning objects in the future based on their ranking values too.

For example, if "Student-Z" had his VAK learning assessment results and the following values had been displayed and recorded for him after the assessment, those values can be used for selecting learning objects based on the percentage and difference between the acquired percents in the assessment results for each topic in the course structure.

Table 1. The VAK result

\begin{tabular}{|l|c|}
\hline Learning Style & Value \\
\hline Visual & $50 \%$ \\
\hline Auditory & $35 \%$ \\
\hline Kinaesthetic & $15 \%$ \\
\hline
\end{tabular}

Next he should select his instructor, so for example he selected "Instructor-X", he will see that his instructor is teaching (Java course). When the student selects this course, a copy of Java course structure will be sent to his learning space, this structure will be an exact copy of the Java e-course structure regarding chapters, and topics, plus an additional added links for new learning objects based on the percent displayed in table 1 and the added constraints mentioned previously. Based on the displayed values, the student will have a maximum of four additional resources of different type with respect to VAK percent results and the available learning objects in the repository, and these resources will be added for each topic in the students e-course structure and they will be highlighted to guide the students learning process based on his adaptability selection and demand.

\section{The complete structure}

Using adaptive unified e-learning repository structure with the benefits and flexibility provided will enhance learning standards and outcomes, by overcoming the obstacles of one-size-fits-all problem and lack of flexibility, which is currently preventing e-learning technology adoption. This will be achieved by adding proper e-content, flexibility, interoperability, and reusability including different adaptability approaches.

The following benefits are expected from the use of the adaptive unified e-learning system:

- Different universities can use this system directly before having their own e-learning system.

- Learners will be presented with the same chance of having different learning objects regardless of the university they attend.

- Learning objects will be afforded in different adaptive manner.

- Instructors will have a better medium for sharing their learning objects among each other The system will be of benefit to users with disabilities since it will provide adaptive learning to suit a learner's needs as well as a unified learning structure with different learning resources.

- The student will have his own learning space, which he can control and manipulate in many ways by modifying the learning content and learning objectives

The system can be used for providing another means of adaptive e-learning, since the structure can be modified to incorporate other adaptive methodologies. 


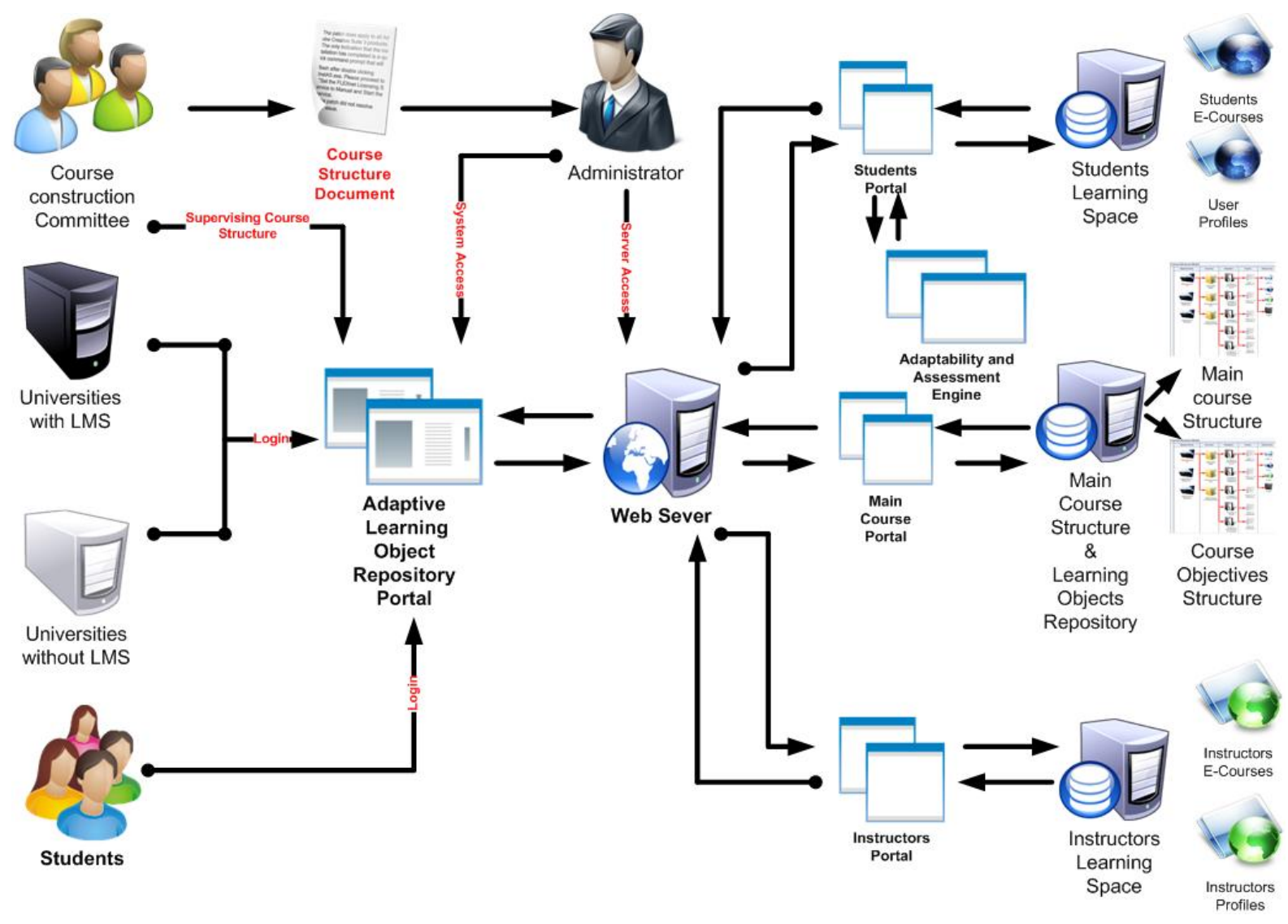

\section{Conclusion}

The need for adaptability within the current learning object repository systems should be considered, If the obstacles that prevent a comprehensive adoption of e-learning are to be overridden. By providing adaptive e-learning to suit a variety of student learning demands and styles, the repository structure proposed here can go a long way in alleviating the burden each university has to bear in terms of effort and finance. With minor changes, the system can be modified to support other innovative adaptability approaches in addition to the previous discussed methods. The system structure can also offer a new adaptable approach such as having a merge approach between more than one adaptable selection. This feature is precisely one of the major strengths of system structure by the flexibility it shows towards incorporating different approaches, as it provides enhanced functionalities and allows a better support for universities, instructors and learners.

\section{References}

[1] L. Lockyer, J. Patterson, B. Harper, "ICT in higher education: evaluating outcomes for health education" ,Journal of Computer Assisted Learning ,Vol. 17 Issue 3 Page 275 September 2001
[2] L. Aroyo, \& Dicheva, D. "The New Challenges for Elearning”, The Educational Semantic Web. Educational Technology \& Society, vol 7 (4), pp 5969. 2004

[3] J. G. Hedberg, The online and digital experience: reassuring higher-order learning outcomes. In L. R.Vandervert, L. V. Shavinina \& R. A. Cornell (Eds.), Cyber education, the future of long distance learning, New York: Mary Ann Liebert, 2001, pp 219-236

[4] A. Jones,. (2009) "Redisciplining Generic Attributes: The Disciplinary Context in Focus" Studies in Higher Education 34(1): pp. 85-100

[5] J. Willems, (2007) "Does Style Matter? Considering the Impact of Learning Styles in E-Learning”, In ICT: Providing choices for Learners and Learning. [online],Available: http://www.ascilite.org.au/conferences/singapore07/pr ocs/willemsposter.pdfascilite Singapore 2007. (Accessed on 7th December 2009)

[6] K. Cuthrell, A. Lyon, (2007) "Instructional Strategies: What Do Online Students Prefer?", Journal of Online Learning and Teaching 3(4):pp. 153-163

[7] N. Matar, S. Khwaldeh and Z. Hunaiti, “ Adaptive Unified E-learning System for Supporting Better Elearning Approach”, Proceedings of the 8th Annual Postgraduate Symposium on the Convergence of 
Telecommunications, Networking and Broadcasting (PGNet 2007), Liverpool John Moores University, UK, 28-29 June 2007

[8] L. Aroyo, R. Mizoguchi, \& C. Tzolov, (2003). OntoAIMS: Ontological Approach to Courseware Authoring. Paper presented at the International Conference on Computers in Education (ICCE2003), December 2-5, 2003, Hong Kong

[9] P. Dolog, N. Henze, W.Nejdl, \& M. Sintek, (2004). The Personal Reader: Personalizing and Enriching Learning Resources Using Semantic Web Technologies. Paper presented at the Third International Adaptive Hypermedia and Adaptive Web-based Systems Conference (AH2004), August 23-26, 2004, Eindhoven, The Netherlands

[10] M. Hatala, G. Richards, T. Eap, and A. Shah, (2007) "Secure Communication Layer for Scalable Networks of Learning Objects Repositories", E-Learning Networked Environments and Architectures pp:276305

[11] M. Peters, and D. Araya, (2008) "Networks, Information Politics And The New Paradigm Of Social Production", Educational Research: Networks and Technologies 2: pp. 33-42

[12] A. El Saddik, and M. Hossain, (2007) "LORNAV: Virtual Reality Tool for Navigation of Distributed Learning Objects Repositories", In: Pierre, S. (ed.) ELearning Networked Environments and Architectures: A Knowledge Processing Perspective. New York: Springer Book Series

[13]. P. Pouyioutas, and M. Poveda, (2005) "Designing a Learning Object Repository-The Views of Higher Education Faculty", Lecture Notes in Computer Science 3583/2005: pp. 111-121

[14] www.lon-capa.org, accessed on 6th December 2010

[15] http://lionshare.its.psu.edu, accessed on 6th December 2010

[16] http://www.kazaa.com , accessed on 12th December 2010

[17] http://www.limewire.com, accessed on 15th December 2010
[18] http://www.gnutellaforums.com, accessed on 15th December 2010

[19] http://www.edutella.org/edutella.shtml, accessed on 16th December 2010

[20] http://pool.iat.sfu.ca/fedsearch/index.jsp, accessed on 16th December 2010

[21] G. Richards, R. McGreal, and N. Friesen, (2002) "Learning Object Repository Technologies For Telelearning: The Evolution of POOL and CanCore", Proceedings of the IS2002, Informing Science + IT Education Conference, June, 2002. Cork, Ireland

[22] T. Duffey, and J. Kirkley, "Learning theory and pedagogy in distance learning”. Learner-Centered Theory and Practice in Distance Education. Mahwah, NJ: Lawrence Erlbaum, 2004

[23] D. Dagger, V. Wade \& O.Conlan, (2005). Personalization for All: Making Adaptive Course Composition Easy. Education Technology \& Society, 8 (3), 9-25

[24] P. De Bra, A. Aerts, D. Smits, \& N. Stash, (2002). AHA! Version 2.0, More Adaptation Flexibility for Authors. Paper presented at the World Conference on e-Learning in Corporate, Government, Healthcare \&Higher Education (ELearn'2002), October 15-19, 2002, Montreal, Canada

[25] M. Kravcik, \& M. Specht, (2004). Flexible Navigation Support in the WINDS Learning Environment for Architecture and Design. Paper presented at the Third International Adaptive Hypermedia and Adaptive Web based Systems Conference (AH2004), August 23-26, 2004, Eindhoven, The Netherlands

[26] P. Brusilovsky, (2001). Adaptive hypermedia. Methods and techniques of adaptive hypermedia. International Journal of User Modeling and UserAdapted Interaction, 11 (1/2), 87-110

[27] P.V. Rosmalen, H. Vogten, R.Van Es, H. Passier , P.Poelmans, \& R. Koper, "Authoring a full life cycle model in standards-based”, adaptive e-learning. Educational Technology \& Society, 9 (1), 2006, 72-83

[28] D. Perkins, “Outsmarting I. Q The Emerging Science of Learnable Intelligence”. New York: The Free Press 1995. 